\title{
Amiloride-Insensitive Currents of the Acid-Sensing Ion Channel-2a (ASIC2a)/ASIC2b Heteromeric Sour-Taste Receptor Channel
}

\author{
Shinya Ugawa, ${ }^{1}$ Takashi Yamamoto, ${ }^{3}$ Takashi Ueda, ${ }^{1}$ Yusuke Ishida, ${ }^{1,2}$ Akira Inagaki, ${ }^{1,2}$ Makoto Nishigaki, ${ }^{1}$ and \\ Shoichi Shimada ${ }^{1}$ \\ Departments of ${ }^{1}$ Anatomy II and ${ }^{2}$ Otorhinolaryngology, Nagoya City University Medical School, Nagoya 467-8601, Japan, and ${ }^{3}$ Department of Behavioral \\ Physiology, Graduate School of Human Sciences, Osaka University, Suita, Osaka 565-0871, Japan
}

Acid-sensing ion channel-2a (ASIC2a) is an amiloride-blockable proton-gated cation channel, probably contributing to sour-taste detection in rat taste cells. To isolate another subtype of the sour-taste receptor, we screened a rat circumvallate papilla cDNA library and identified ASIC2b, an N-terminal splice variant of ASIC2a. Reverse transcription-PCR analyses confirmed the expression of ASIC2b transcripts in the circumvallate papilla and, moreover, demonstrated its expression in the foliate and fungiform papillae. Immunohistochemical analyses revealed that ASIC2b, as well as ASIC2a, was expressed in a subpopulation of taste cells in the circumvallate, foliate, and fungiform papillae, and some of the cells displayed both ASIC2a and ASIC2b immunoreactivities. Subsequent coimmunoprecipitation studies with circumvallate papillae extracts indicated that ASIC2b associated with ASIC2a to form assemblies and, together with our immunohistochemical findings, strongly suggested that both ASIC2 subunits formed heteromeric channels in taste cells in the circumvallate, foliate, and fungiform papillae. Oocyte electrophysiology demonstrated that the ASIC2a/ASIC2b channel generated maximal inward currents at a $\mathrm{pH}$ of $\leq 2.0$, which is in agreement with the in vivo $\mathrm{pH}$ sensitivity of rat taste cells, and that the amiloride sensitivity of the heteromer decreased with decreasing $\mathrm{pH}$ and was almost completely abolished at a $\mathrm{pH}$ of 2.0. These findings provide persuasive explanations for the amiloride insensitivity of acid-induced responses of rat taste cells.

Key words: proton; sour; acid-sensing ion channel (ASIC); immunoprecipitation; electrophysiology; amiloride

\section{Introduction}

Sour taste is essentially a proton taste, and proton-sensitive ion channels that are apically and basolaterally located in taste cells are believed to act as sour-taste receptors (Gilbertson et al., 2000; Lindemann, 2001). The activation of sour-taste receptors provokes taste cell depolarization, which is accompanied by a decrease in intracellular $\mathrm{pH}$ in the cells (Lyall et al., 2001), leading to transmitter release onto gustatory afferent neurons.

Which channel molecule functions as a receptor for sour tastants in mammalian species? In the hamster, amiloride-blockable proton currents were recorded during acid-induced responses in taste cells that also exhibited amiloride-blockable $\mathrm{Na}^{+}$currents in the absence of external protons. Therefore, amilorideblockable epithelial sodium channels implicated in the taste of sodium salts have been proposed to contribute to sour-taste transduction (Herness and Gilbertson, 1999). In the rat, hyperpolarization-activated cyclic nucleotide-gated $(\mathrm{HCN})$ channels $\mathrm{HCN} 1$ and HCN4 are expressed in a subset of taste cells. These $\mathrm{HCN}$ channels can be directly activated by extracellular protons and may act as sour-taste receptors (Stevens et al., 2001). In the mouse, apically located proton-activated cation channels and ba-

Received Dec. 17, 2002; revised Feb. 11, 2003; accepted Feb. 20, 2003.

This work was supported by research grants from the Japan Society for the Promotion of Science (to S.U. and S.S.)

Correspondence should be addressed to Dr. Shinya Ugawa, Department of Anatomy II, Nagoya City University Medical School, 1 Kawasumi, Mizuho-cho, Mizuho-ku, Nagoya 467-8601, Japan. E-mail: ugawa@med.nagoya-cu.ac.jp.

Copyright @ 2003 Society for Neuroscience $\quad$ 0270-6474/03/233616-07\$15.00/0 solaterally located chloride channels, of which the molecular identities remain to be elucidated, play important roles in detecting sour-taste stimuli (Miyamoto et al., 2000).

We recently reported that a proton-activated cation channel, acid-sensing ion channel-2a (ASIC2a) [previously called mammalian degenerin-1 (MDEG1) and also known as BNCla and $\mathrm{BNaC1} \alpha$ (Waldmann and Lazdunski, 1998; Price et al., 2000; Duggan et al., 2002)], is expressed at both apical and basolateral membranes of rat taste cells in the circumvallate papilla, implying the involvement of ASIC2a in sour-taste reception (Ugawa et al., 1998). However, this simultaneously raises discrepancies to be addressed. First, acidic stimuli elicited action potentials from rat taste cells in a dose-dependent manner with decreasing $\mathrm{pH}$, with maximal responses at a $\mathrm{pH}$ of $<2.0$ (Pfaffmann et al., 1967), although the ASIC2a channel generates its maximal currents at a $\mathrm{pH}$ of $\sim 3.0$ (Ugawa et al., 2001). Second, the acid-induced responses of rat taste cells were barely suppressed by amiloride (Ninomiya and Funakoshi, 1988), whereas the ASIC2a currents were amiloride blockable.

Using a combination of molecular biological, morphological, and electrophysiological approaches, we show here that ASIC2b associates with ASIC2a to form a heteromeric complex in rat taste cells, modifying the $\mathrm{pH}$ sensitivity of the ASIC2a channel. ASIC2b, an N-terminal splice variant of ASIC2a, was first isolated from rat dorsal root ganglion neurons and functions as a modulatory subunit of ASIC channels (Lingueglia et al., 1997). We also show that the currents of the ASIC2a/ASIC2b heteromer are amiloride insensitive in strongly acidic conditions that have been 
used as sour-taste stimuli in most previous electrophysiological recordings in the taste system. Our data support the idea that members of the ASIC family of cation channels play significant roles in sour-taste reception in mammals.

\section{Materials and Methods}

The Center of Experimental Animal Sciences at Nagoya City University gave us permission for the following experiments.

Molecular cloning of ASIC2b. A rat circumvallate papilla cDNA library was screened at low stringency as described previously (Saishin et al., 1997). A partial rat ASIC2a cDNA, corresponding to nucleotides 12422553 (GenBank/European Bioinformatics Institute Data Bank accession number U53211), was labeled with $\left[\alpha-{ }^{32} \mathrm{P}\right]$ deoxyCTP (random priming; Amersham Pharmacia Biotech, Tokyo, Japan) and used as a probe. DNA sequence analysis was performed by the dideoxy chain termination method.

Reverse transcription-PCR. Male Wistar rats were anesthetized with Nembutal (50 mg/kg, i.p.) and decapitated. Poly(A) ${ }^{+}$RNAs were isolated from the circumvallate/foliate/fungiform papillae and tongue epithelial tissue (no taste papillae) using a FastTrack 2.0 Kit (Invitrogen, San Diego, CA). The resulting $1 \mu \mathrm{g}$ of poly(A) ${ }^{+}$RNA from the taste papillae and $2 \mu \mathrm{g}$ of poly $(\mathrm{A})^{+}$RNA from the tongue epithelial tissue were reverse transcribed using SuperScript II reverse transcriptase (Invitrogen), and $1 / 20$ th of the sample was amplified by PCR for 35 cycles with oligonucleotide primers: for ASIC2b, 5' -TGGTTCCGCAAACTGGCCGACTT-3' (forward) and 5' -AGGAAAGAAGTCGAGTCCCATCT-3' (reverse); for $\beta$-actin, $5^{\prime}$-GATCCTGACCGAGCGTGGCTACA-3' (forward) and 5' ACGGATGTCAACGTCACACTTCA-3' (reverse). The molecular identity of the resulting PCR fragments was checked by DNA sequencing.

Antibody production. A synthetic peptide containing an N-terminal cysteine and rat ASIC2b residues 49-65 (QGPGVARRGRPSLSRTK) was conjugated to a keyhole limpet hemocyanin using $m$-maleimidobenzoyl- $N$-hydroxysuccinimide ester. The conjugated proteins were used to raise polyclonal ASIC2b antibodies in rabbits (female New Zealand rabbits) by standard procedures. The polyclonal rabbit serum reactive with rat ASIC2a residues 1-16 (MDLKESPSEGSLQPSS) was described previously (Ugawa et al., 1998). Both ASIC2a and ASIC2b antisera were affinity-purified using a ProtOn Kit 1 (Multiple Peptide Systems, San Diego, CA), and resultant fractions 3-5 of each antibody were used for the following experiments.

Western blotting. Rat circumvallate papillae, dorsal root ganglia, and ASIC2b-expressing (or water-injected) oocytes (for details, see section below discussing oocyte electrophysiology) were homogenized in $50 \mathrm{~mm}$ Tris-HCl, pH 7.5, 5 mm EDTA, $150 \mathrm{~mm} \mathrm{NaCl}$, 1\% Triton X-100, and complete protease inhibitors (Roche Diagnostics, Basel, Switzerland). Equal amounts of protein $(20 \mu \mathrm{g})$ were resolved by SDS-PAGE $(10 \%)$ and transferred to polyvinylidene difluoride membranes (Immobilon-P; Millipore, Bedford, MA). An ASIC2b preimmune serum and the affinitypurified anti-ASIC2b (or anti-ASIC2a) antibody were diluted 1:1000 and 1:2500 (or 1:500), respectively, in a block solution containing 10\% skim milk and $0.3 \%$ Tween 20 in Tris-buffered saline (TBS-T), and incubated with membranes overnight at $4^{\circ} \mathrm{C}$. After washing three times in TBS-T solution, blots were detected with an alkaline phosphatase-labeled goat antirabbit IgG antibody (Roche Diagnostics) and visualized with a 5-bromo-4-chlor-indolyl-phosphate-nitroblue tetrazolium indicator substrate. Controls included use of water-injected oocytes and preabsorption of the diluted primary antibodies with each synthetic antigen $\left(10^{-6} \mathrm{M}\right)$ for $1 \mathrm{hr}$ at room temperature before incubation with the membranes.

Immunohistochemistry. Fresh frozen sections (2-8 $\mu$ m thick) of the circumvallate, foliate, and fungiform papillae of Wistar rats were fixed in a $4 \%$ paraformaldehyde-phosphate buffer for $30 \mathrm{~min}$ at $4^{\circ} \mathrm{C}$; washed three times in a phosphate buffer; blocked for $4 \mathrm{hr}$ in 5\% skim milk, 5\% normal goat serum, $1 \%$ BSA, and $0.3 \%$ Triton X-100; and then incubated overnight at $4^{\circ} \mathrm{C}$ with the anti-ASIC2b antibody diluted 1:2000 in the block solution. (For ASIC2a, the primary antibody diluted 1:500 in the block solution was used instead.) This was followed by a Cy3-conjugated antirabbit IgG secondary antibody (Amersham Biosciences, Tokyo, Ja- pan), and the slides were observed using a fluorescence microscope (Nikon, Tokyo, Japan). To demonstrate colocalization of both ASIC2 proteins, the same experiments were performed on contiguous semithin sections $(2 \mu \mathrm{m})$, and images of double-labeled cells were colorized and combined with Adobe Photoshop software (Adobe Systems, San Jose, CA). Neither preimmune sera showed any immunoreactivity (data not shown).

Coimmunoprecipitation. Rat circumvallate papillae were lysed on ice in $10 \mathrm{vol}$ of a coimmunoprecipitation buffer $(20 \mathrm{~mm}$ Tris- $\mathrm{HCl}, 150 \mathrm{~mm}$ $\mathrm{NaCl}, 1 \% \mathrm{NP}-40,100 \mu \mathrm{g} / \mathrm{ml}$ DNase, $50 \mu \mathrm{g} / \mathrm{ml}$ RNase A, 1 mм PMSF, 1 $\mu \mathrm{g} / \mathrm{ml}$ leupeptin, $1 \mu \mathrm{g} / \mathrm{ml} N$ - $\alpha$-tosyl-L-phenylalanine chloromethyl ketone, $1 \mu \mathrm{g} / \mathrm{ml} \mathrm{N}$ - $\alpha$-tosyl-L-lysine chloromethyl ketone, and $1 \mu \mathrm{g} / \mathrm{ml} \mathrm{pep-}$ statin, $\mathrm{pH}$ 7.4) using a glass Teflon homogenizer. Lysates were collected and then clarified by spinning in a microfuge for $15 \mathrm{~min}$ at $4^{\circ} \mathrm{C}$. For each immunoprecipitation, $250 \mu \mathrm{l}$ of the supernatant was precleared for $12 \mathrm{hr}$ at $4^{\circ} \mathrm{C}$ with $10 \mu \mathrm{l}$ of a normal rabbit serum plus $25 \mu \mathrm{l}$ of BSA-coated protein A-Sepharose beads (Pierce, Rockford, IL). The cleared samples were mixed with the anti-ASIC2a or -ASIC2b antibody ( $5 \mu \mathrm{g})$ overnight at $4^{\circ} \mathrm{C}$ and then with BSA-coated protein A-Sepharose beads for $3 \mathrm{hr}$ at $4^{\circ} \mathrm{C}$. After washing five times in a phosphate buffer, the Sepharose-bound proteins were analyzed by Western blot analyses. As negative controls, the same experiments were performed in parallel using each preimmune serum or a buffer solution (used for the affinity purification and dilution of the antibodies) instead of the ASIC2a or ASIC2b antibody.

Oocyte electrophysiology. The procedures used were basically the same as those described previously (Inoue et al., 1995; Ugawa et al., 2001). Stage V-VI Xenopus laevis oocytes defolliculated with collagenase (Sigma, St. Louis, MO) were injected with each ASIC2 (ASIC2a or ASIC2b) cRNA alone ( $25 \mathrm{ng}$ ) or with a combination of both cRNAs ( $25 \mathrm{ng}$ each) in a final volume of $50 \mathrm{nl}$. The extracellular recording solution (ND140) contained (in mM): $140 \mathrm{NaCl}, 2 \mathrm{KCl}, 1.8 \mathrm{CaCl}_{2}, 1 \mathrm{MgCl}_{2}$, and 5 HEPES, $\mathrm{pH}$ 7.5. Acidic solutions (adjusted with $\mathrm{HCl}$ to the $\mathrm{pH}$ values indicated in the figures) were buffered with $5 \mathrm{~mm}$ MES, $\mathrm{pH}$ 6.5-5.0, or homopiperazine- $N, N^{\prime}$-bis(2-ethanesulfonic acid), $\mathrm{pH} \leq 4.5$, instead of HEPES. In some experiments, ND140 solutions, $\mathrm{pH} 4.0$, containing 10 $\mathrm{mm}$ acetic acid or $10 \mathrm{~mm}$ sucrose (adjusted with $\mathrm{HCl}$ to the $\mathrm{pH}$ value) were used as stimulus solutions. All macroscopic currents were recorded at $-70 \mathrm{mV}$.

\section{Results \\ Expression of ASIC2b in rat taste cells in the circumvallate, foliate, and fungiform papillae}

To solve the discrepancies (see Introduction), we made efforts to isolate another subtype of the sour-taste receptor. We screened a rat circumvallate papilla cDNA library with a partial ASIC2a cDNA probe at low stringency and obtained several independent clones. The longest cDNA clone showed high homology with ASIC2a and turned out to be identical to ASIC2b (previously called MDEG2). To confirm the presence of ASIC2b mRNA in the circumvallate papilla, reverse transcription (RT)-PCR experiments were performed (Fig. 1). It was found that the expected 504 bp fragments were observed in the circumvallate papillae cDNA (lane 1), whereas no detectable signal was seen in the circumvallate papillae sample without reverse transcriptase (lane 2) or in the tongue epithelial tissue (no taste papillae) cDNA (lane 7). Moreover, the experiments revealed that the ASIC2b fragments were detected in the foliate and fungiform papillae cDNAs (lanes 3 and 5, respectively), whereas no signal was seen in any taste papilla sample without reverse transcriptase (lanes 4 and 6). On the basis of these results, we further continued RT-PCR, leading to the isolation of the full-length ASIC2b cDNA from the foliate and fungiform papillae (data not shown). All of these results indicated that the circumvallate papilla clearly expressed ASIC2b transcripts, and that the foliate and fungiform papillae did also. [We cloned the full-length ASIC2a cDNA as well from 


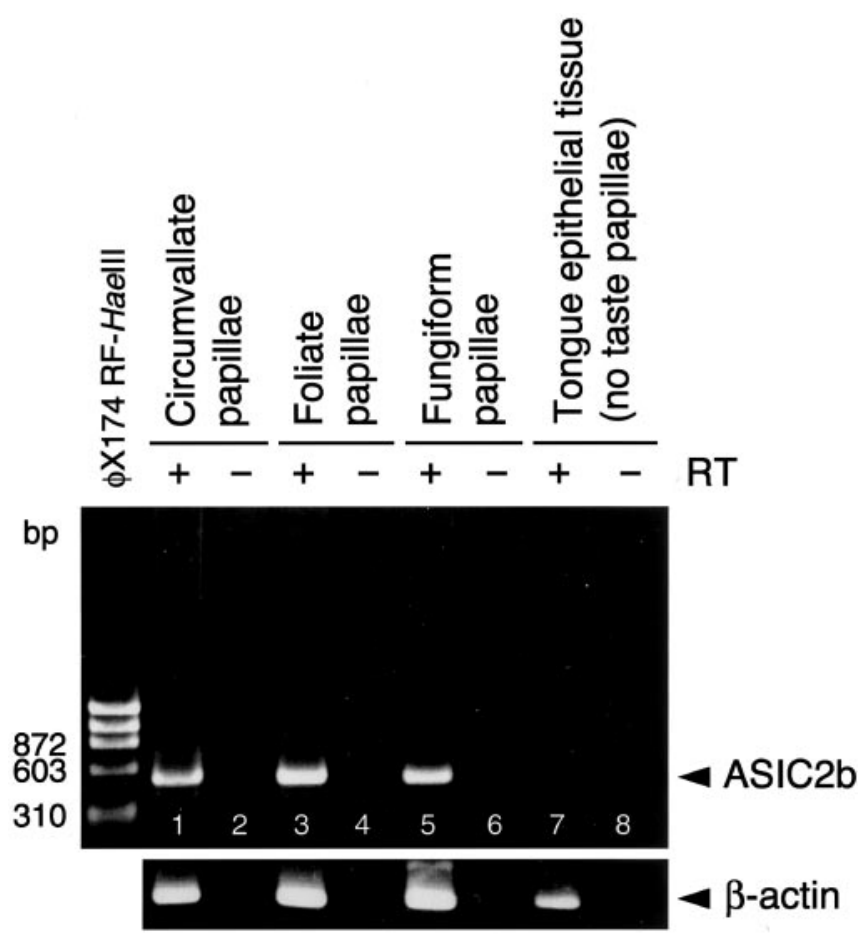

Figure 1. RT-PCR analysis of ASIC2b mRNA expression. PCR fragments corresponding to the $\mathrm{N}$-terminal region of ASIC $2 \mathrm{~b}$ were observed in the circumvallate, foliate, and fungiform papillae cDNAs (lanes 1,3,5), whereas no detectable signal was seen in the circumvallate, foliate, or fungiform papillae sample without reverse transcriptase (lanes 2, 4, 6) or in the tongue epithelial tissue (no taste papillae) CDNA (lane 7). Lane 8, Tongue epithelial tissue sample without reverse transcriptase. Control $\beta$-actin fragments are shown in the bottom part. The size of DNA standards is indicated on the left ( $\phi$ X174 RF-HaellI).

the foliate and fungiform papillae using an RT-PCR method (data not shown).]

ASIC2b expression in the rat tongue at the protein level was confirmed by Western blotting (Fig. 2). Circumvallate samples were subjected to the analyses, because the papilla contains a larger number of taste buds than the foliate and fungiform papillae. Using a rabbit antibody generated against ASIC2b amino acids $49-65$, a single prominent band of $\sim 70 \mathrm{kDa}$ was detected in extracts of the circumvallate papillae (lane 2), whereas the preimmune serum did not detect the blots (lane 1). Preabsorption with $10^{-6} \mathrm{M} \mathrm{ASIC} \mathrm{b}_{49-65}$ peptide prevented the labeling of the blots (lane 3). This antibody also recognized a single band of similar molecular size in extracts of dorsal root ganglia (lane 4), which have high levels of ASIC2b protein expression (Alvarez de la Rosa et al., 2002), and the same preabsorption treatment completely abolished the staining (lane 5). The molecular weight of the labeled protein in the circumvallate papillae extracts was slightly higher than that of the ASIC2a-immunoreactive band (lane 8). The amino acid sequences of ASIC2b and ASIC2a proteins differ in their N-terminal portions (Lingueglia et al., 1997), including the regions used to raise each antipeptide antibody, and ASIC2b is 51 aa longer than ASIC2a. Therefore, the size of the $\sim 70 \mathrm{kDa}$ blots was quite reasonable. In addition, we examined the specificity of the anti-ASIC2b peptide antibody using an in vitro expression system and found that a single band was detected in extracts of ASIC2b-expressing oocytes (lane 6), whereas no immunoreactivity was seen in extracts of water-injected controls (lane 7). The size of the band was slightly lower than the blots in extracts of the circumvallate papillae and dorsal root ganglia (lanes 2 and 4, respectively), probably because of differences in

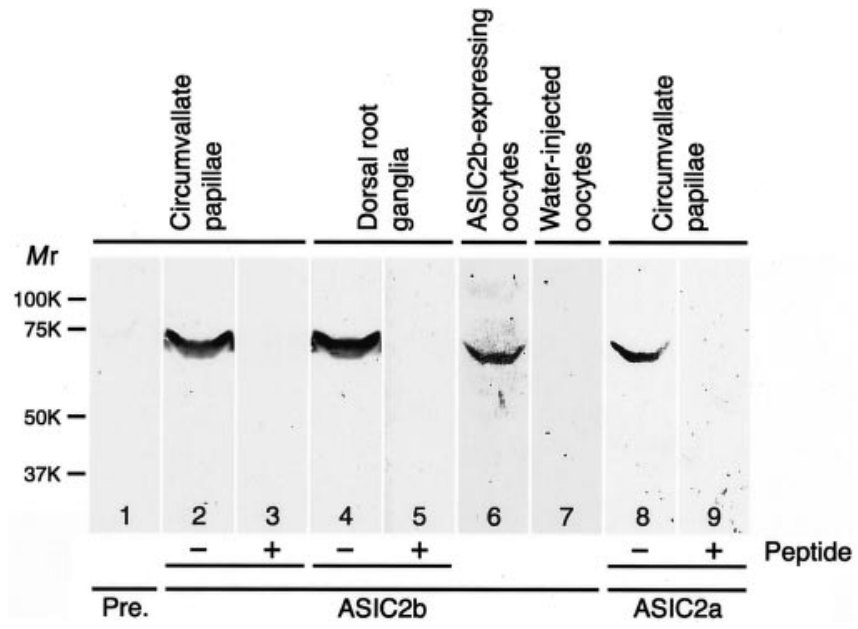

Figure 2. Expression of ASIC $2 b$ protein in rat circumvallate papilla. ASIC $2 b$ expression at the protein level was confirmed by Western blot analyses. Using a rabbit antibody generated against ASIC2 b amino acids $49-65$, single prominent bands of $\sim 70 \mathrm{kDa}$ blots were detected in extracts of the circumvallate papillae and dorsal root ganglia (lanes 2, 4; Peptide, -), whereas the preimmune serum did not detect the blots in the circumvallate papillae extracts (lane 1, Pre.). Preabsorption with $10^{-6} \mathrm{M} \mathrm{ASIC2b_{49-65 }}$ peptide prevented the labeling of the blots (lanes 3, 5, Peptide, + ). The same antibody recognized a single band in extracts of ASIC2b-expressing 0ocytes (lane 6), whereas no immunoreactivity was seen in extracts of water-injected oocytes (lane 7). The molecular weight of the ASIC2b-immunoreactive protein in the circumvallate papillae extracts was slightly higher than that of the ASIC2aimmunoreactive band (compare lane 2 with lane 8). Preabsorption with $10^{-6} \mathrm{M} \mathrm{ASIC2}_{1-16}$ peptide prevented the labeling of the ASIC2a blots (lane 9). Molecular mass standards are indicated on the left $\left(M_{\mathrm{r}}\right)$.

glycosylation. These results demonstrated that the antibody raised against the ASIC2b sequence was specific for ASIC2b, and that the rat circumvallate papilla clearly expressed ASIC2b proteins.

Immunohistochemical analyses of ASIC2b expression in the circumvallate papilla were performed. The analyses revealed that ASIC2b-immunoreactive cells occurred in taste buds but were not detected in the surrounding lingual epithelia (Fig. 3A). At the cellular level, intense ASIC2b immunoreactivity was detected in a subset of taste cells (Fig. 3B). As reported previously (Ugawa et al., 1998), ASIC2a-immunoreactive cells were also found exclusively in taste buds (Fig. 3D), and their immunoreactivities were observed in a subpopulation of taste cells (Fig. 3E). These immunoreactions were prevented when each antibody was preabsorbed with $10^{-6} \mathrm{M}$ synthetic peptide that was used to immunize rabbits (Fig. 3C,F). Both proteins were expressed in all taste buds in the circumvallate papillae examined.

We next performed the same experiments on other taste papillae and found that ASIC2b and ASIC2a proteins were localized in a subset of taste cells in the foliate (Fig. 3, G, $H$ and $J, K$, respectively) and fungiform (Fig. 3, $M, N$ and $P, Q$, respectively) papillae. Preabsorption with $10^{-6} \mathrm{M}$ antigen peptide of each antibody prevented the immunostainings (Fig. 3I,L,O,R). Together, we concluded that both ASIC2 proteins were expressed in a subset of taste cells in rat circumvallate, foliate, and fungiform taste papillae.

\section{ASIC2a/ASIC2b heteromeric complex in rat taste cells}

Immunohistochemistry on contiguous semithin sections $(2 \mu \mathrm{m}$ thick) was performed to determine whether ASIC2a and ASIC2b were colocalized within single taste cells (Fig. 4). It showed that both ASIC2 proteins were coexpressed in a subset of taste cells in 

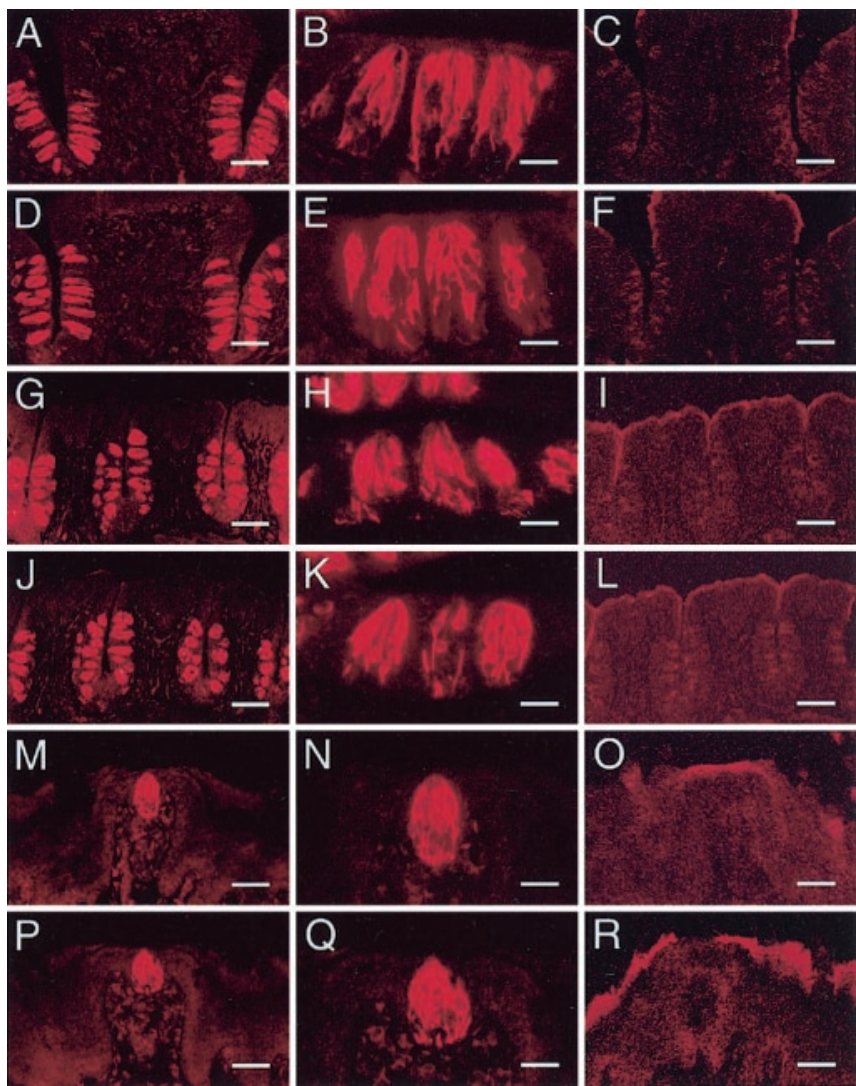

Figure 3. Localization of ASIC2 subunits by immunohistochemistry. A-C, Fluorescence micrographs of circumvallate papillae immunostained with an anti-ASIC $2 b$ antibody in the $a b-$ sence $(A, B)$ or presence $(C)$ of $10^{-6} \mathrm{M} \mathrm{ASIC} \mathrm{b}_{49-65}$ peptide. $D-F$, Circumvallate papillae immunostained with an anti-ASIC2a antibody in the absence $(D, E)$ or presence $(F)$ of $10^{-6} \mathrm{M}$ ASIC $2 a_{1-16}$ peptide. $G-L$, Fluorescence micrographs of foliate papillae immunostained with the anti-ASIC2b antibody in the absence $(G, H)$ or presence $(I)$ of the $10^{-6} \mathrm{M}$ ASIC2b antigen peptide and with the anti-ASIC2a antibody in the absence $(J, K)$ or presence $(L)$ of the $10^{-6} \mathrm{M}$ ASIC2a antigen peptide. $M-R$, Fluorescence micrographs of fungiform papillae immunostained with the anti-ASIC $2 \mathrm{~b}$ antibody in the absence $(M, N)$ or presence $(0)$ of the $10^{-6} \mathrm{M}$ ASIC2b antigen peptide and with the anti-ASIC2a antibody in the absence $(P, Q)$ or presence $(R)$ of the $10^{-6} \mathrm{M}$ ASIC2a antigen peptide. Both ASIC2b and ASIC2a proteins were localized in a subset of taste cells in the circumvallate, foliate, and fungiform papillae in the rat. Scale bars: $A, C, D, F, G$, I, J, L, $100 \mu \mathrm{m} ; B, E, H, K, N, Q, 25 \mu \mathrm{m} ; M, 0, P, R, 50 \mu \mathrm{m}$.

the circumvallate (top row), foliate (middle row), and fungiform (bottom row) papillae. Regrettably, we failed to estimate the extent of the colocalization, because preparation of such thin, adjacent, and morphologically fine sections was quite difficult. Our results mean that ASIC2a and ASIC2b proteins were, at least in part, colocalized in a subpopulation of taste cells in the papillae. Heteromeric assemblies of both ASIC2 proteins in heterologous expression systems have been described previously (Lingueglia et al., 1997; Ugawa et al., 2001), so these results raise the possibility that ASIC2a/ASIC2b complexes are expressed in native rat taste cells.

We then performed coimmunoprecipitation studies to confirm the ASIC2 assembly biochemically (Fig. 5). Circumvallate papillae extracts were studied. ASIC2a/ASIC2b complexes were detected in immunoprecipitated fractions with an anti-ASIC2b or anti-ASIC2a antibody (lanes 3 and 6, respectively), but not in those with each preimmune antiserum (lanes 1 and 4, respectively) or with a buffer solution used for the purification and dilution of both antibodies (lanes 2 and 5). These results clearly indicate that ASIC2a/ASIC2b complexes were present in the ex-

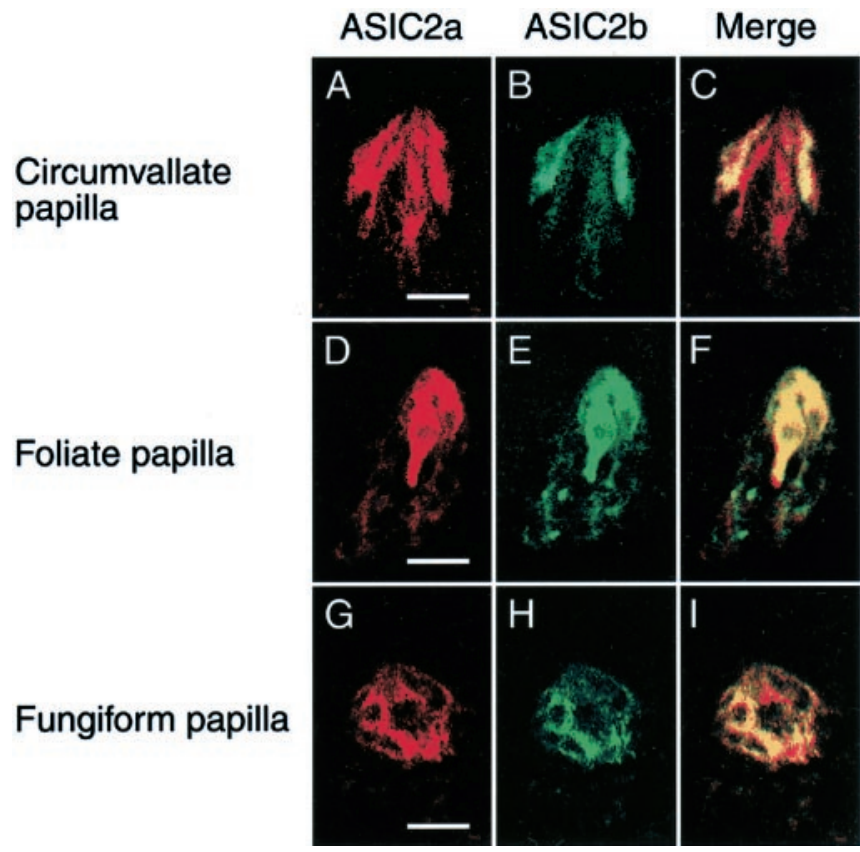

Figure 4. Colocalization of ASIC2a and ASIC2b within single taste cells. Immunohistochemical analyses with anti-ASIC $2 \mathrm{a}$ and anti-ASIC $2 \mathrm{~b}$ antibodies were performed on contiguous semithin sections $(2 \mu \mathrm{m})$. Red represents ASIC2a staining in rat circumvallate, foliate, and fungiform papillae $(A, D$, and $G$, respectively), and green represents $A S I C 2 b$ staining in the papillae $(B, E$, $H$ ). Regions of overlap (Merge) are yellow $(C, F, I)$. Both ASIC2a and ASIC2b proteins were, at least in part, colocalized in a subpopulation of taste cells in the circumvallate (top), foliate (middle), and fungiform (bottom) papillae. Scale bars, $25 \mu \mathrm{m}$.

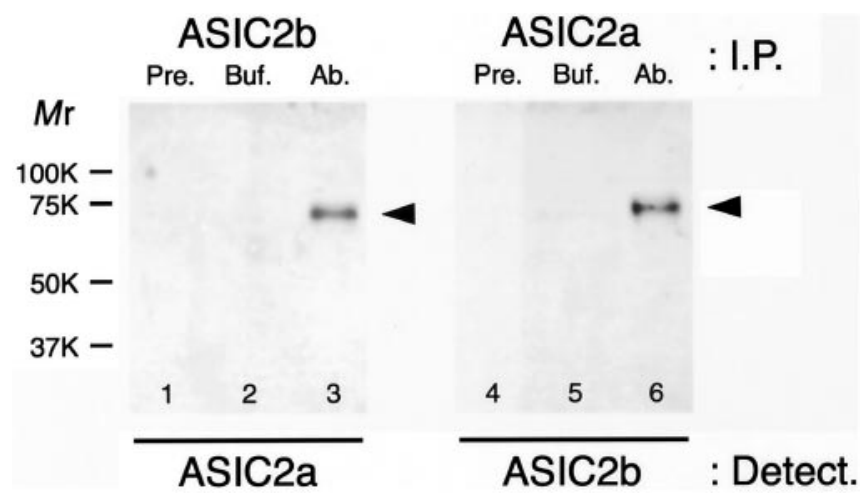

Figure 5. Coimmunoprecipitation of ASIC2a and ASIC2b. Detergent-solubilized proteins of rat circumvallate papillae were subjected to the immunoprecipitation (I.P.) studies. ASIC2a/ ASIC2b heteromeric complexes were detected (Detect.) in immunoprecipitated fractions with an anti-ASIC2b or anti-ASIC2a antibody (Ab.) (lanes 3 and 6, respectively), but not in those with each preimmune antiserum (Pre.) (lanes 1 and 4, respectively) or with a buffer solution used for purification and dilution of both antibodies (Buf.; lanes 2, 5). Molecular mass standards are indicated on the left $\left(M_{r}\right)$.

tracts. Together with our immunohistochemical observations, these results strongly suggest that ASIC2a and ASIC $2 \mathrm{~b}$ form heteromeric assemblies in a subset of taste cells in rat circumvallate papillae and also suggest that the ASIC2 assemblies are also located in a subset of taste cells in the foliate and fungiform papillae.

\section{ASIC2b modifies inactivation kinetics and $\mathrm{pH}$ dependence of ASIC2a}

We analyzed the electrophysiological properties of the ASIC2a/ ASIC2b heteromeric complex using an X. laevis oocyte mRNA translation system with a two-electrode voltage clamp. It was 
A

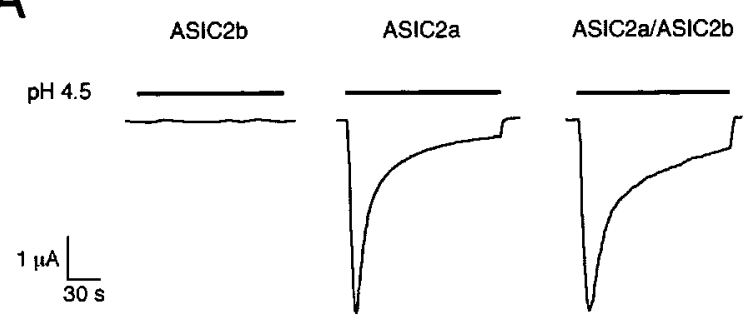

B

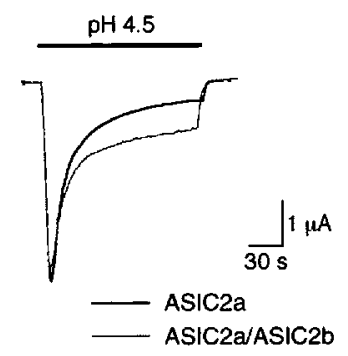

C

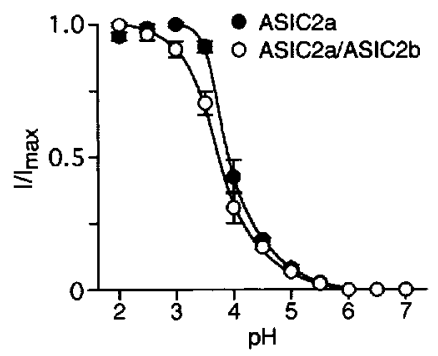

D

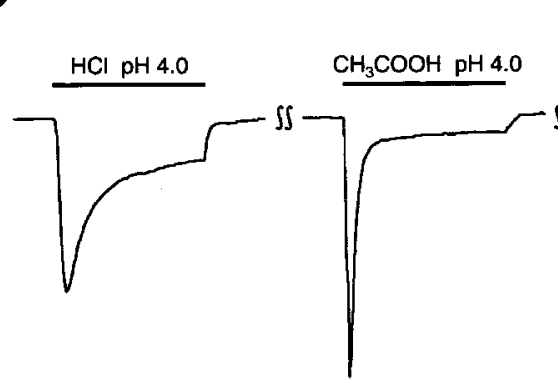

F

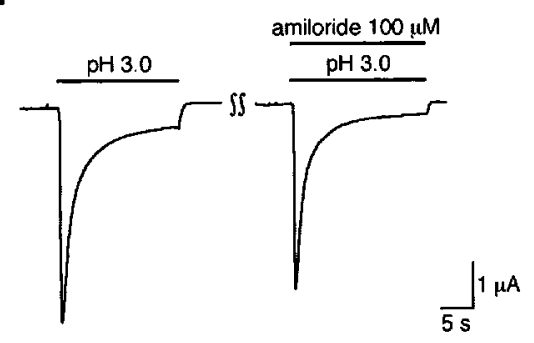

sucrose $10 \mathrm{mM}$

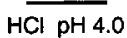

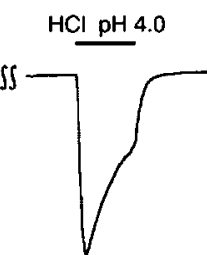

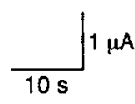

G

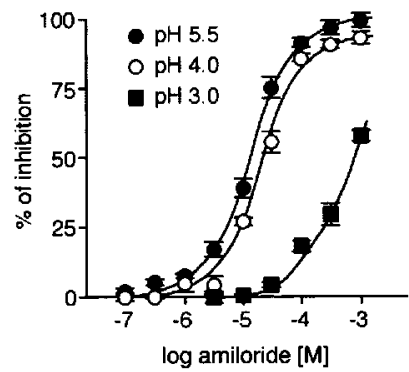

E

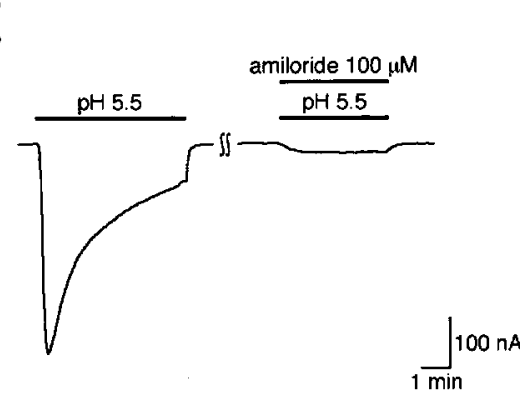

H

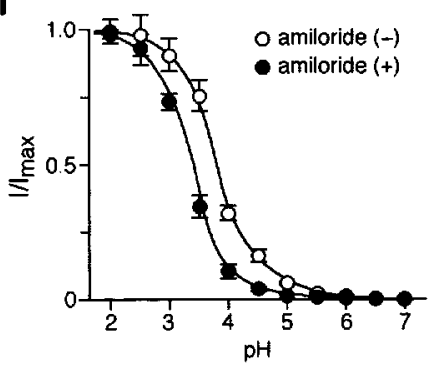

Figure 6. Functional expression of ASIC2a and ASIC2b. A, B, Representative whole-cell current traces of ASIC2 homomeric and heteromeric channels expressed in X. laevis oocytes. Acidic pH solutions were present in the bath during times indicated by bars. $C$, Dose-response curves for the extracellular pH. The proton-activated currents increased in a pH-dependent manner with decreasing extracellular $\mathrm{pH}$ in the range of $6.5-2.0$ in oocytes expressing ASIC2a/ASIC2b heteromers, whereas ASIC2a homomers generated maximal inward currents at $\mathrm{pH} \sim 3.0$. Shown are mean values \pm SEM from 25 experiments, respectively. D, Representative proton ( $\mathrm{pH} 4.0$ )-induced currents of ASIC2a/ASIC2b-expressing 00 cytes in the absence or presence of acetic acid. Stimulation by acidic solutions containing $10 \mathrm{~mm}$ acetic acid $\left(\mathrm{CH}_{3} \mathrm{COOH}, \mathrm{pH} 4.0\right)$ generated a larger amplitude of the peak currents than that induced by hydrochloric acid solutions $(\mathrm{HCl}, \mathrm{pH} 4.0)$ at equal $\mathrm{pH}$, whereas the $10 \mathrm{~mm}$ sucrose solutions, final pH 4.0, showed no apparent effects on the proton-induced currents. $E-H$, Relationship between stimulating pH values and amiloride sensitivity of the ASIC2a/ASIC2b heteromer. The whole-cell current induced by a rapid pH drop from 7.5 to 5.5 was almost completely blocked by $100 \mu m$ amiloride $(E)$, whereas the same amiloride treatment barely reduced the current induced by a rapid pH drop from 7.5 to 3.0 ( $F$ ). The inhibitory effect of $100 \mu \mathrm{m}$ amiloride was attenuated in a pH-dependent manner with decreasing $\mathrm{pH}$ ( $G$ ). The $x$ - and $y$-axes in $G$ represent concentrations of amiloride and percentage of blocked currents (compared with the maximal induced current at each $\mathrm{pH}$ value), respectively. The $\mathrm{pH}$ dependency of the heteromer was shifted to more acidic $\mathrm{pH}$ values in the presence of $100 \mu \mathrm{m}$ amiloride $(H)$. The values in $G$ and $H$ represent mean \pm SEM of at least five experiments.

confirmed that ASIC2b was inactive by itself but interacted with ASIC2a to form heteromers with new properties, as described previously (Lingueglia et al., 1997; Ugawa et al., 2001). In response to rapid changes in extracellular $\mathrm{pH}$ from 7.5 to 4.5 , ASIC2a/ASIC2b heteromers desensitized with a biphasic inactivation kinetic that was not seen on expression of ASIC2a alone (Fig. 6A,B). In oocytes expressing ASIC2a homomers, protonactivated inward currents were increased with decreasing $\mathrm{pH}$ of the extracellular solutions in the range of 6.5-3.0, with a maximal response at a $\mathrm{pH}$ of 3.0, whereas the ASIC2a/ASIC2b heteromeric channel generated maximal inward currents at a $\mathrm{pH}$ of $\leq 2.0$ (Fig. $6 C)$. Thus, ASIC $2 \mathrm{~b}$ modifies the inactivation process and $\mathrm{pH}$ dependency of the ASIC2a channel.

The ASIC2a channel activity can be enhanced by acetic acid (Ugawa et al., 1998), so we examined the effect of the acid on the ASIC2a/ASIC2b channel. We prepared ND140 solutions containing $10 \mathrm{~mm}$ acetic acid, final $\mathrm{pH} 4.0$, and applied them to
ASIC2a/ASIC2b-expressing oocytes (Fig. 6D). Intriguingly, at equal $\mathrm{pH}$, stimulation by the acetic acid solutions $\left(\mathrm{CH}_{3} \mathrm{COOH}\right.$, $\mathrm{pH}$ 4.0) generated a larger amplitude of the peak currents than that induced by ND140 solutions containing hydrochloric acid, final $\mathrm{pH}$ 4.0. The $10 \mathrm{~mm}$ sucrose solutions of the same final $\mathrm{pH}$ showed no apparent effects on the proton ( $\mathrm{HCl}, \mathrm{pH} 4.0)$-induced currents. These results indicate that an acetic acid molecule, but not a concomitant increment in osmotic pressure, increased the peak amplitude for some unknown reason. These findings may account for the well known taste phenomenon that acetic acid is more sour than hydrochloric acid at equal $\mathrm{pH}$.

\section{Relationship between amiloride sensitivity of the ASIC2a/ ASIC2b channel and $\mathrm{pH}$ values of acidic stimuli} The inhibitory effect of amiloride on the ASIC2a/ASIC2b channel currents evoked by different $\mathrm{pH}$ stimuli was investigated on condition that both ASIC2 subunits fulfilled their functions as a het- 
eromer. In response to rapid $\mathrm{pH}$ changes from 7.5 to 5.5 , the heteromer generated fast-rising and slowly desensitizing inward currents that were almost completely blocked by $100 \mu \mathrm{M}$ amiloride (Fig. $6 E$ ). In contrast, the same amiloride treatment barely reduced the inward currents at a $\mathrm{pH}$ of 3.0 (Fig. $6 \mathrm{~F}$ ). The inhibitory effect was attenuated in a $\mathrm{pH}$-dependent manner with decreasing extracellular $\mathrm{pH}$ (Fig. 6G). $\mathrm{IC}_{50}$ (inhibition constant) values of the heteromer under $\mathrm{pH}$ shifts to 5.5 and 4.0 were $4.5 \pm$ $1.0 \mu \mathrm{M}$ (mean $\pm \mathrm{SEM} ; n=7)$ and $22.0 \pm 4.2 \mu \mathrm{M}(n=9)$, respectively, and the value under the $\mathrm{pH}$ shift to 3.0 was likely to range between 700 and $900 \mu \mathrm{M}(n=5)$.

We also examined the effect of $100 \mu \mathrm{M}$ amiloride on the $\mathrm{pH}$ dependency of the ASIC2a/ASIC2b heteromeric channel activity (Fig. $6 H$ ). Although its maximal whole-cell current was not affected by the amiloride treatment, the $\mathrm{pH}$ dependency of the heteromer shifted to more acidic $\mathrm{pH}$ values compared with those in the absence of the drug. The half-points for activation of the ASIC2a/ASIC2b channel current in the absence and presence of $100 \mu \mathrm{M}$ amiloride were $\mathrm{pH} 3.9 \pm 0.2(n=7)$ and $\mathrm{pH} 3.4 \pm 0.2$ $(n=9)$, respectively. It is noteworthy that the amiloride sensitivity of the ASIC2a/ASIC2b channel was markedly reduced at a $\mathrm{pH}$ of $\leq 3.0$ and almost completely abolished at a $\mathrm{pH}$ of 2.0. [Under extremely low $\mathrm{pH}$ conditions, amiloride sensitivity of the ASIC2a channel was also attenuated (data not shown).] These results imply that the heteromer functions as an amilorideinsensitive proton-activated cation channel under strongly acidic conditions.

\section{Discussion}

We successfully isolated the ASIC2b cDNA from the rat tongue using a combination of homology screening and RT-PCR approaches. According to our immunohistochemical and coimmunoprecipitation studies, ASIC2a and ASIC2b were colocalized within a subset of taste cells in the circumvallate, foliate, and fungiform papillae, and both proteins probably formed heteromeric assemblies in the cells. The ASIC2a/ASIC2b channels are likely to be expressed at least in type III cells that make synaptic contacts with gustatory afferent neurons, because ASIC2a is so, as reported previously (Ugawa et al., 1998). These findings raise the possibility that extracellular protons dissociated from sour-taste substances depolarize taste cells through the activation of the ASIC2a/ASIC2b complex, which leads to transmitter release onto gustatory neurons.

As described previously (Lingueglia et al., 1997; Ugawa et al., 2001) and shown by our present electrophysiology (Fig. 6A-C), ASIC2b conferred new properties on the ASIC2a channel. ASIC2b interacts with ASIC2a to attenuate ASIC2a channel desensitization, suggesting that ASIC2b may intensify sour-taste sensation by prolonging depolarizing phases of taste cells, and, more importantly, that ASIC2b lowers the $\mathrm{pH}$ sensitivity of the ASIC2a channel. In our experiments, proton-induced currents of the ASIC2a/ASIC2b heteromer were recorded in the $\mathrm{pH}$ range of 7.5-1.0. We could not obtain the precise electrophysiological properties of the channel at a $\mathrm{pH}$ of $\leq 1.5$, because such acidic stimuli were too severe for the oocytes to be stably clamped at a holding potential, but greater incremental responses than those at a $\mathrm{pH}$ of 2.0 were frequently observed. On the basis of these findings, we speculate that the heteromer may generate its maximal currents at a $\mathrm{pH}$ of $<2.0$, which is in accordance with in vivo acid-evoked responses of rat taste cells (Pfaffmann et al., 1967). The involvement of ASIC2b subunit in sour-taste reception may thus be essential for fine discrimination of sour tastants.

Both ASIC2a and ASIC2b subunits belong to the ASIC family of cation channels. Members of this family form proton-activated channels in the mammalian central and peripheral nervous systems (Waldmann and Lazdunski, 1998). Our present study did not identify other family members such as ASIC1a (also known as $\mathrm{BNaC2}$ ), ASIC1b (a splice variant of ASIC1a), ASIC3 (also known as dorsal root acid-sensing ion channel), and ASIC4 (also known as spinal cord acid-sensing ion channel) in rat taste cells (Chen et al., 1998; Waldmann and Lazdunski, 1998; Akopian et al., 2000; Gründer et al., 2000; Bässler et al., 2001; Duggan et al., 2002). According to recent reports, however, ASIC1 and ASIC4 are present in mammalian taste cells (Liu and Simon, 2001; Lin et al., 2002). In addition, ASIC3 is also located in taste cells in rat circumvallate papilla in our preliminary RT-PCR and immunohistochemical experiments (our unpublished observations). Previous electrophysiological experiments recorded a variety of taste-receptor potentials in response to acidic stimuli in the rat (Ozeki and Sato, 1972). Therefore, it is possible that each taste cell uses various combinations of ASIC subunits to detect mucosal protons. In this sense, it is quite natural that ASIC2-null mice exhibited no apparent deficits in sour-taste transduction (Kinnamon et al., 2000), and it would be of interest to determine the precise stoichiometry of taste ASIC channels.

Amiloride sensitivity is a common notable feature of ASIC channels. However, according to numerous previous observations, acid-evoked responses of rat taste cells were barely suppressed by amiloride, so it has been highly controversial whether an amiloride-sensitive sour-taste transduction pathway really exists in the rat. Amiloride inhibited gustatory neural responses to hydrogen chloride in the hamster and rat, but its inhibitory effect was restricted to acid-evoked responses in sodium-selective nerve fibers (N-best fibers), which primarily carry information for salty taste (Ninomiya and Funakoshi, 1988; Hettinger and Frank, 1990). In other words, proton-induced responses recorded in acid-selective nerve fibers (H-best fibers) that carry information for sour taste were not inhibited by amiloride in those animals.

To solve this riddle, we investigated the amiloride sensitivity of the ASIC2a/ASIC2b channel in various $\mathrm{pH}$ conditions and found that it dramatically decreased at a $\mathrm{pH}$ of $\leq 3.0$ and was almost completely abolished at a $\mathrm{pH}$ of 2.0. These findings provide persuasive explanations for the amiloride insensitivity of rat sour-taste transduction, because most previous electrophysiological experiments used strongly acidic conditions, $\mathrm{pH} \leq 3.0$, as sour-taste stimuli. Under mildly acidic conditions, protoninduced responses of rat taste cells may be considerably inhibited by amiloride, and, in such cases, it comes as no surprise that the ASIC2a/ASIC2b channel contributes to sour-taste responses even in H-best fibers. Actually, $200 \mu \mathrm{M}$ amiloride completely suppressed depolarizing responses of rat taste cells to mild acidification, pH 4.9 (Liu and Simon, 2001). Citric acid (pH 5.0)induced taste cell responses contained an amiloride-blockable component in the rat (Lin et al., 2002).

According to imaging experiments, extracellular application of acids generates intracellular $\mathrm{pH}$ decreases in rat taste cells (Lyall et al., 1997), indicating that the cells contain some proton entry mechanisms in the apical or basolateral membranes. Those $\mathrm{pH}$ decreases correlated well with the magnitude of acid-evoked taste nerve responses, so taste cell intracellular acidification is proposed as a proximate sour-taste stimulus in recent publications (DeSimone et al., 2001; Lyall et al., 2001). In our preliminary electrophysiological studies, acidic recording solutions, $\mathrm{pH}$ 2.0, that contained no cations besides protons induced large inward currents in ASIC2a/ASIC2b-expressing oocytes (data not shown). This finding suggests that protons themselves are able to 
penetrate the activated ASIC2a/ASIC2b channel, and that the channel may contribute to intracellular acidification of rat taste cells. However, rat saliva contains millimolar concentrations of $\mathrm{Na}^{+}$, and protons and $\mathrm{Na}^{+}$compete in many channels, including amiloride-blockable epithelial sodium channels implicated in the taste of sodium salts in the hamster (Herness and Gilbertson, 1999). To determine whether the ASIC2a/ASIC2b channel contributes to taste cell intracellular acidification under the normal physiological condition, more extensive studies are needed in the future.

\section{References}

Akopian AN, Chen CC, Ding Y, Cesare P, Wood JN (2000) A new member of the acid-sensing ion channel family. NeuroReport 11:2217-2222.

Alvarez de la Rosa D, Zhang P, Shao D, White F, Canessa CM (2002) Functional implications of the localization and activity of acid-sensitive channels in rat peripheral nervous system. Proc Natl Acad Sci USA 99:2326-2331.

Bässler EL, Ngo-Anh TJ, Geisler HS, Ruppersberg JP, Gründer S (2001) Molecular and functional characterization of acid-sensing ion channel (ASIC) 1b. J Biol Chem 276:33782-33787.

Chen CC, England S, Akopian AN, Wood JN (1998) A sensory neuronspecific, proton-gated ion channel. Proc Natl Acad Sci USA 95:10240-10245.

DeSimone JA, Lyall V, Heck GL, Feldman GM (2001) Acid detection by taste receptor cells. Respir Physiol 129:231-245.

Duggan A, García-Añoveros J, Corey DP (2002) The PDZ domain protein PICK1 and the sodium channel $\mathrm{BNaC} 1$ interact and localize at mechanosensory terminals of dorsal root ganglion neurons and dendrites of central neurons. J Biol Chem 277:5203-5208.

Gilbertson TA, Damak S, Margolskee RF (2000) The molecular physiology of taste transduction. Curr Opin Neurobiol 10:519-527.

Gründer S, Geissler HS, Bässler EL, Ruppersberg JP (2000) A new member of acid-sensing ion channels from pituitary gland. NeuroReport 11:16071611.

Herness MS, Gilbertson TA (1999) Cellular mechanisms of taste transduction. Annu Rev Physiol 61:873-900.

Hettinger TP, Frank ME (1990) Specificity of amiloride inhibition of hamster taste responses. Brain Res 513:24-34.

Inoue K, Sakaitani M, Shimada S, Tohyama M (1995) Cloning and expression of a bovine glutamate transporter. Brain Res Mol Brain Res 28:343-348.

Kinnamon SC, Price MP, Stone LM, Lin W, Welsh MJ (2000) The acidsensing ion channel BNC1 is not required for sour taste transduction. Paper presented at the XII International Symposium on Olfaction and Taste 104, Brighton, UK, July.
Lin W, Ogura T, Kinnamon SC (2002) Acid-activated cation currents in rat vallate taste receptor cells. J Neurophysiol 88:133-141.

Lindemann B (2001) Receptors and transduction in taste. Nature 413:219225.

Lingueglia E, de Weille JR, Bassilana F, Heurteaux C, Sakai H, Waldmann R, Lazdunski M (1997) A modulatory subunit of acid sensing ion channels in brain and dorsal root ganglion cells. J Biol Chem 272:29778-29783.

Liu L, Simon SA (2001) Acidic stimuli activates two distinct pathways in taste receptor cells from rat fungiform papillae. Brain Res 923:58-70.

Lyall V, Feldman GM, Heck GL, DeSimone JA (1997) Effects of extracellular $\mathrm{pH}, \mathrm{PCO}_{2}$, and $\mathrm{HCO}_{3}{ }^{-}$on intracellular $\mathrm{pH}$ in isolated rat taste buds. Am J Physiol 273:C1008-C1019.

Lyall V, Alam RI, Phan DQ, Ereso GL, Phan TH, Malik SA, Montrose MH, Chu S, Heck GL, Feldman GM, DeSimone JA (2001) Decrease in rat taste receptor cell intracellular $\mathrm{pH}$ is the proximate stimulus in sour taste transduction. Am J Physiol 281:C1005-C1013.

Miyamoto T, Fujiyama R, Okada Y, Sato T (2000) Acid and salt responses in mouse taste cells. Prog Neurobiol 62:135-157.

Ninomiya Y, Funakoshi M (1988) Amiloride inhibition of responses of rat single chorda tympani fibers to chemical and electrical tongue stimulations. Brain Res 451:319-325.

Ozeki M, Sato M (1972) Responses of gustatory cells in the tongue of rat to stimuli representing four taste qualities. Comp Biochem Physiol A 41:391-407.

Pfaffmann C, Fisher GL, Frank MK (1967) The sensory and behavioral factors in taste preferences. In: Olfaction and taste II (Hayashi T, ed), pp 361-381. Oxford: Pergamon.

Price MP, Lewin GR, McIlwrath SL, Cheng C, Xie J, Heppenstall PA, Stucky CL, Mannsfeldt AG, Brennan TJ, Drummond HA, Qiao J, Benson CJ, Tarr DE, Hrstka RF, Yang B, Williamson RA, Welsh MJ (2000) The mammalian sodium channel $\mathrm{BNC1}$ is required for normal touch sensation. Nature 407:1007-1011.

Saishin Y, Shimada S, Morimura H, Sato K, Ishimoto I, Tano Y, Tohyama M (1997) Isolation of a cDNA encoding a photoreceptor cell-specific actinbundling protein: retinal fascin. FEBS Lett 414:381-386.

Stevens DR, Seifert R, Bufe B, Müller F, Kremmer E, Gauss R, Meyerhof W, Kaupp UB, Lindemann B (2001) Hyperpolarization-activated channels HCN1 and HCN4 mediate responses to sour stimuli. Nature 413:631-635.

Ugawa S, Minami Y, Guo W, Saishin Y, Takatsuji K, Yamamoto T, Tohyama M, Shimada S (1998) Receptor that leaves a sour taste in the mouth. Nature 395:555-556.

Ugawa S, Ueda T, Minami Y, Horimoto M, Shimada S (2001) A single amino acid substitution in MDEG2 specifically alters desensitization of the proton-activated cation current. NeuroReport 12:2141-2145.

Waldmann R, Lazdunski M (1998) $\mathrm{H}^{+}$-gated cation channels: neuronal acid sensors in the NaC/DEG family of ion channels. Curr Opin Neurobiol 8:418-424. 